Research Article

\title{
Influence of Different Chemical Preservatives on the Quality Attrib- utes of Mango Loquat Blended Pulp at Ambient Conditions
}

\section{Rukhsar Ali* and Ali Muhammad}

Department of Food Science and Technology, The University of Agriculture, Peshawar, Khyber Pakhtunkhwa, Pakistan.

\begin{abstract}
Storage stability of mango and loquat blended pulp was conducted to study the effect of selected food chemical preservatives i.e. sodium benzoate (SB), potassium metabisulphite (KMS) and potassium sorbate (PS) on physicochemical qualities (total soluble solids, $\mathrm{pH}$, acidity, phenolic compounds, total sugars, antioxidant activity, Vitamin $\mathrm{C}$ content) and sensory evaluation as color, taste, and overall acceptability stored at ambient conditions $\left(25 \pm 2^{\circ} \mathrm{C}\right)$ for six months with twenty days interval. Based on sensory analysis, the best suitable blend was selected within different ratios of mango pulp and loquat pulp. The blended pulp with ratio $(60: 40)$ got the highest mean score of judges for overall acceptability which used for further study. The different treatments were included in this study as $\mathrm{MLBPr}_{0}$ was control with no preservatives, $\mathrm{MLBPr}_{1}$ having 0.1\% PS, $\mathrm{MLBPr}_{2}$ having 0.1\% KMS, $\mathrm{MLBPr}_{3}$ having 0.1\% SB, MLBPr $\mathrm{r}_{4}$ having $0.05 \% \mathrm{PS}$ and $0.05 \% \mathrm{KMS}$ ), $\mathrm{MLBPr}_{5}$ having $0.05 \%$ PS and $0.05 \% \mathrm{SB}$ ), MLBPr ${ }_{6}$ has $0.05 \% \mathrm{KMS}$ and $0.05 \% \mathrm{S.B}$ ), and $\mathrm{MLBPr}_{7}$ having $0.033 \% \mathrm{PS}+0.033 \% \mathrm{KMS}$ and $0.033 \% \mathrm{SB}$ ). The results highlighted that values of antioxidant activity, total phenolic compounds, and ascorbic acid were found decrease, while total soluble solids and titratable acidity showed an increase during storage. Control sample without preservatives $\left(\mathrm{MLBP}_{\mathrm{r} 0}\right)$ blemished within one month of storage period. Different treatments preserved with food chemical preservatives were statistically significant during storage period of six months at $(\mathrm{p}<0.05)$. From this research work, it has been accomplished that the effect of collective dosage of chemical food preservatives i.e. $0.033 \%$ PS, $0.033 \% \mathrm{SB}$, and 0.01\% KMS on treatment $\mathrm{MLBP}_{\mathrm{r} 7}$ and $\mathrm{MLBP}_{\mathrm{r} 6}$ of mango loquat blended pulp samples were more suitable for enhancing the overall quality of blended pulp and showed maximum stability in physiochemical study and over-all acceptability as compared to other treatments during entire storage.

Received | February 25, 2021; Accepted | May 22, 2021; Published | May 28, 2021

*Correspondence | Rukhsar Ali, Department of Food Science and Technology, The University of Agriculture, Peshawar, Khyber Pakhtunkhwa, Pakistan; Email: ruhi_175@yahoo.com

Citation | Ali, R. and A. Muhammad. 2021. Influence of different chemical preservatives on the quality attributes of mango loquat blended pulp at ambient conditions. Sarhad Journal of Agriculture, 37(2): 564-572.

DOI | https://dx.doi.org/10.17582/journal.sja/2021/37.2.564.572

Keywords | Mango and Loquat, Blended pulp, Sodium benzoate, Potassium metabisulphite, Potassium sorbate
\end{abstract}

\section{Introduction}

$\mathrm{M}$ ango (Mangiferaindica L.) is one of the most cultivated tropical fruits in the world, with over 25.1 million tons of world annual production (Akhtar et al., 2009). Asia is accounted for approximately $77 \%$ of the global mango production and America and Africa are considered for $33 \%$ and $9 \%$, respectively
(FAOSTAT, 2020). Mango is very economical and popular tropical fruit throughout the world due to its high nutritional compositions such as fiber, vitamins, minerals with other phytochemical compounds, and excellent eating quality as well as attractive flavor, taste, aroma, texture, and bright color. That's why mango is considered the King of Fruits (Gerbaud, 2008). Loquat (Eriobotrya japonica Lindl.), originated 
in China and belongs to Rosaceae family has been widely cultivating for commercial purposes since the $19^{\text {th }}$ century. Pakistan is one of the countries with the largest planted area and the main producer of Loquat in Southern Asia (Patricia et al., 2010). Loquat fruit can be eaten fresh as well as combined with other fruits in fruit salads, used as a pie filling and made into sauces and gelatin desserts, jam and jellies (Jonathan et al., 2009). An increase in loquat consumption is due to its health and nutritional benefits which is rich source of Vitamin A, needed for the visual and dental health of an individual. Loquat fruit is very useful in maintaining optimum health due to low level of cholesterol and saturated fats. It is rich in fiber and suitable for losing weight. Loquat is a complex of mallic acid, tartaric acid, citric acid, vitamins A, B and C, and B17 (Federico et al., 2009). Due to high concentration of pectin in Loquat, it is required in industrial processing in the manufacturing of jellies and jams (Hasegawa et al., 2010).

Since the postharvest life of Loquat fruit is very limited, therefore its consumption in fresh form is accordingly limited (Cai et al., 2006). Coping with seasonality and the limitation of production areas, one way to increase availability to the consumer and even more value to the end product is processing or industrialization, by preparation of juices, jams and jellies (Hasegawa et al., 2010). To avoid post-harvest losses of fruits during peak seasons as well as losses to farmers, there is a need to prepare value-added fruit products to overcome nutrient deficiencies as well. By applying different respective methods, value addition is processed to enhance the value of the commodity. The original product is possible to be converted into different products e.g. jam, jellies, blended juices and pickles etc. (Parveen et al., 2014).

The main objective of this research study is to minimize post-harvest losses of mango and loquat fruit by preserving the pulp with different chemical preservatives and to enhance the overall quality by blending mango and loquat pulp.

\section{Materials and Methods}

\section{Raw materials (Mango and Loquat fruit) collection and preparation}

Fresh and good quality fruit of Mango (Chaunsa variety) and Loquat (Desi variety) was taken in crates from Fruit Market Peshawar to Food
Processing Lab of NIFA (Nuclear Institute for Food and Agriculture), Tarnab, Peshawar, where the experiments were conducted. To remove the adhering dust and extraneous material, the fruits were washed gently with clean water. Diseased or bruised fruits of mango and loquat were removed.

\section{Pulp extraction from mango and loquat fruit}

Mango and Loquat fruits were peeled off with stainless steel knives and cut into small pieces and seedy portions were removed. To avoid oxidation of mango and loquat fruit pieces were dipped in 0.2 $\%$ citric acid solution. Mango and loquat pulp were extracted with help of a pulping machine.

The individually extracted pulp of mango and loquat was mixed in different ratios. The sensory evaluation of different ratios of mango and loquat blended pulp was carried out by judges to find out the most acceptable blended pulp ratio. The Mango pulp and Loquat pulp were blended with ratio 90:10, 80:20, 70:30, 60:40, and 50:50 respectively. The sensory evaluation results revealed that mango loquat blended pulp ratio (60:40) $60 \%$ of mango and $40 \%$ of loquat pulp secured the highest score for color, flavor, taste and overall acceptability among all blended pulp treatments which was continued for further analysis.

\section{Plan of study}

The acceptable blend (60:40) of Mango and Loquat pulp was mixed with an individual and combined dosage of food chemical preservatives. The treatments were as $\operatorname{MLBPr}_{0}$ was control with no preservatives, $\mathrm{MLBPr}_{1}$ having $0.1 \% \mathrm{PS}, \mathrm{MLBPr}_{2}$ having $0.1 \%$ $\mathrm{KMS}, \mathrm{MLBPr}_{3}$ having $0.1 \% \mathrm{SB}, \mathrm{MLBPr}_{4}$ having $0.05 \%$ PS and $0.05 \% \mathrm{KMS}$ ), MLBPr M $_{5}$ having $0.05 \%$ PS and $0.05 \% \mathrm{SB}$ ), MLBPr ${ }_{6}$ having $0.05 \% \mathrm{KMS}$ and $0.05 \% \mathrm{SB}$ ), and $\mathrm{MLBPr}_{7}$ having $0.033 \% \mathrm{PS}+0.033 \%$ KMS and $0.033 \% \mathrm{SB}$ ). The chemically preserved samples were filled in plastic jars and stored at ambient temperature $\left(25 \pm 2^{0} \mathrm{C}\right)$ for six months.

\section{Physico-chemical analysis and sensory evaluation study}

Different treatments of mango and loquat blended pulp was investigated for physicochemical qualities (total soluble solids, $\mathrm{pH}$, titratable acidity, reducing and non-reducing sugars, and Vitamin $\mathrm{C}$ content) using the procedure (AOAC, 2012). Spectrophotometric methods were used for the determination of total phenolic compounds stated by (Sadasivam and Manicam, 2008) while DPPH free radical scavenger 
calculation procedures (Goupy et al., 1999) were used for the determination of total antioxidant activity. Sensory evaluation was carried out by procedure of (Larmond, 1997). All the investigations were carried out with twenty days interval stored for six months at ambient conditions $\left(25 \pm 2^{\circ} \mathrm{C}\right)$.

\section{Statistical analysis}

Results of all samples were accumulated and examined by Statistix 8.1. The effects of all treatments were analyzed by two factorial CRD (Complete Randomized Design), and means separation was carried out by LSD test at level of significance $(0.05 \%)$ as stated by Steel and Torrie (1997).

\section{Results and Discussion}

\section{$p H$ and titratable acidity}

The mango and loquat blended pulp samples data obtained for $\mathrm{pH}$ showed a decrease during storage conditions at ambient condition. During six months storage, decline was observed for $\mathrm{pH}$ from 4.43 to 3.62. The data for $\mathrm{pH}$ decrease (Figure 1) were as $\mathrm{MLBPr}_{0}$ from 4.44 to $3.04, \mathrm{MLBPr}_{1}$ from (4.43 to 3.71), $\operatorname{MLBPr}_{2}$ (4.42 to 3.75), for $\mathrm{MLBPr}_{3}$ from (4.44 to 3.26) during storage studies. Likewise, $\mathrm{pH}$ data were recorded for $\mathrm{MLBPr}_{4}$ (4.42 to 3.73), $\mathrm{MLBPr}_{5}$ from (4.43 to 3.69), $\mathrm{MLBPr}_{6}$ from (4.44 to 3.86) and $\mathrm{MLBPr}_{7} \mathrm{pH}$ decrease was recorded (4.43 to 3.92). The highest percent decrease was recorded for $\mathrm{pH}$ in the blended fruit pulp treatments in $\mathrm{MLBPr}_{0}$ (31.53\%) and followed by $\operatorname{MLBPr}_{3}(26.58 \%)$ while the lowest percent decrease in blended fruit pulp treatments was noted in $\operatorname{MLBPr}_{7}(11.51 \%)$ followed by $\operatorname{MLBPr}_{6}(13.06 \%)$. All the data were significantly different for $\mathrm{pH}$ of mango and loquat blended fruit pulp at $(p<0.05)$. These results are in line with Mir et al. (2019) who reported decrease in $\mathrm{pH}$ values of mango pulp treated with different chemical food preservatives during the storage period. The results of our research work are in agreement with the outcomes of Hussain et al. (2008) in which the $\mathrm{pH}$ decreased and acidity increased in blended juice of apple and apricot at ambient storage temperature. The reason behind the increase in acidity and decrease in $\mathrm{pH}$ is the conversion of non-reducing sugar and pectin into acid compounds which elevate the acidity during mango pulp storage (Mir et al., 2019).

The percent acidity increased of blended pulp samples at room temperature during storage study. The mean values for percent acidity increase observed from 0.62 to 1.22 . Percent acidity increase (Figure 2 ) for $\mathrm{MLBPr}_{0}$ was recorded (0.62 to 1.68 ) (0.62 to 1.42 ) for $\operatorname{MLBPr}_{1,}(0.63$ to 1.32$)$ for $\mathrm{MLBPr}_{2}$ and for $\mathrm{MLBPr}_{3}$ the values were (0.63 to 1.36 ) during 180 days of storage period. Likewise, data for percent acidity recorded were $\mathrm{MLBPr}_{4}$ from (0.63 to 0.93), for $\operatorname{MLBPr}_{5}$ (0.62 to 1.28), $\operatorname{MLBPr}_{6}$ from (0.63 to 1.02$)$ and $\mathrm{MLBPr}_{7}$ increased in percent acidity observed from (0.62 to 0.81$)$. $\operatorname{MLBPr}_{0}(63.10 \%)$ got maximum percent increase in titratable acidity of blended pulp followed by $\mathrm{MLBPr}_{1}(55.63 \%)$, while $\mathrm{MLBPr}_{7}$ (23.46\%) got minimum percent increase in blended pulp samples and followed by $\operatorname{MLBPr}_{4}(32.26 \%)$. All the data were significantly different for percent acidity of mango and loquat blended pulp at $(\mathrm{p}<0.05)$. The outcomes of this research work are in agreement with the findings of Hussain et al. (2008) in which the $\mathrm{pH}$ decreased and acidity increased in blended juice of apple and apricot at ambient temperature. The reason behind the increase in acidity and decrease in $\mathrm{pH}$ is the conversion of non-reducing sugar and pectin into acid compounds which increases the acidity during mango pulp storage (Mir et al., 2019).

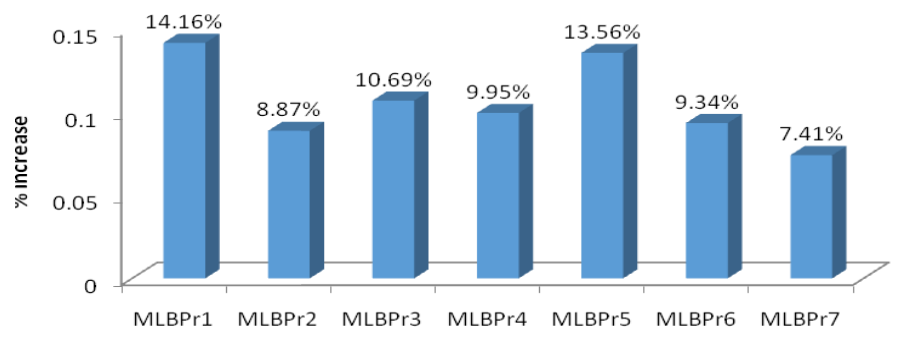

Figure 1: Influence of different food chemical preservatives on the ph of mango and loquat blended pulp at ambient condition $\left(25 \pm 2^{\circ} \mathrm{C}\right)$. MLBP: Mango Loquat Blended Pulp.

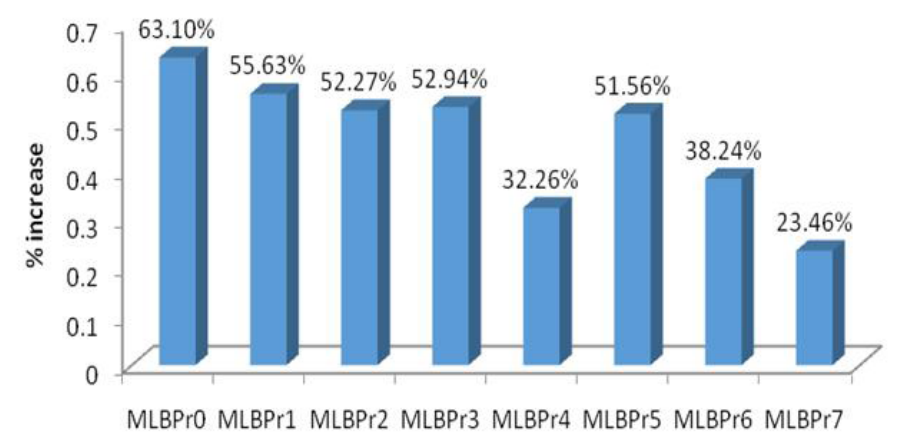

Figure 2: Influence of differentfood chemical preservatives on the titratable acidity of mango and loquat blended pulp at ambient condition $\left(25 \pm 2^{\circ} \mathrm{C}\right)$. MLBP: Mango Loquat Blended Pulp.

Total soluble solids, reducing and non-reducing sugars The TSS increased in blended fruit pulp samples at June 2021 | Volume 37 | Issue 2 | Page 566 
ambient temperature during storage study of 180 days. The mean values for TSS increase observed from 12.11 to 13.30 during six month storage period of blended pulp. The treatment without chemical preservatives (control) expired within 20 days of storage condition. Total soluble solids increase (Figure 3) for MLBPr was recorded (12.12 to 14.12), for $\operatorname{MLBPr}_{2}$ (12.12 to 13.30) and $\mathrm{MLBPr}_{3}$ the values were (12.11 to 13.56) during 180 days of storage period. Likewise, data for total soluble solids recorded were $\mathrm{MLBPr}_{4}$ from (12.13 to 13.47), for $\operatorname{MLBPr}_{5}$ (12.11 to 14.01), $\operatorname{MLBPr}_{6}$ (12.13 to 13.38), and $\mathrm{MLBPr}_{7}$ increased in total soluble solids observed from (12.12 to 13.09). $\operatorname{MLBPr}_{1}(14.16 \%)$ got maximum percent increase in total soluble solids of the blended pulp and followed by $\operatorname{MLBPr}_{5}(13.56 \%)$, while $\operatorname{MLBPr}_{7}(7.41 \%)$ got minimum percent increase in blended pulp samples and followed by $\operatorname{MLBPr}_{2}(8.87 \%)$. All the data were significantly different for total soluble solids of mango and loquat blended pulp at $(\mathrm{p}<0.05)$. The results of Kumhar et al. (2014) were similar to our data who found an increment in the total soluble solids of apple pulp at room condition during a storage study period of four months. Inline outcomes were obtained by Jain and Nema (2007) who observed an increment in the total soluble solids of chemically preserved pulp of guava fruit during storage. This increase was mainly due to the breakdown of complex carbohydrates in simple carbohydrates (Kumar et al., 2015).

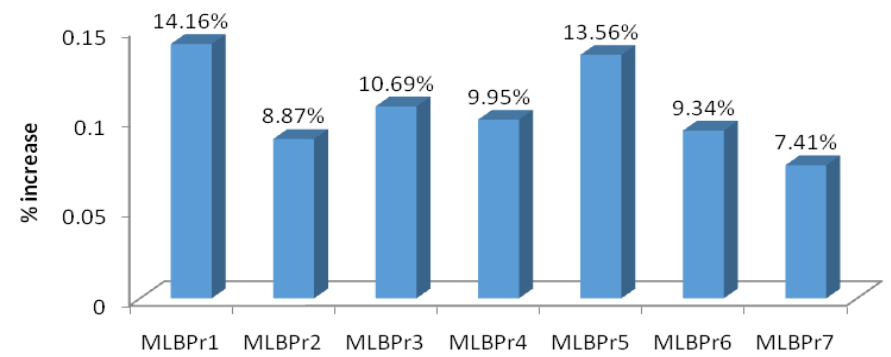

Figure 3: Influence of different food chemical preservatives on the TSS of mango and loquat blended pulp at ambient temperature $\left(25 \pm 2^{\circ} \mathrm{C}\right)$. MLBP: Mango Loquat Blended Pulp

An increase was shown in reducing sugars of blended fruit pulp treatments at room temperature during entire storage study. The mean values for reducing sugars increase observed from 4.11 to 5.34 of blended pulp. The treatment without chemical preservatives (control) expired within 20 days of storage condition. Reducing sugars increase (Figure 4) for $\mathrm{MLBPr}_{1}$ was recorded (4.12 to 6.23), for $\operatorname{MLBPr}_{2}$ (4.11 to 5.38) and $\mathrm{MLBPr}_{3}$ the values were (4.11 to 5.71) during 180 days of storage period. Likewise, data for reducing sugars recorded were $\mathrm{MLBPr}_{4}$ from (124.10 to 5.57), $\operatorname{MLBPr}_{5}$ (4.12 to 6.03), $\operatorname{MLBPr}_{6}$ (4.11 to 5.45), and $\mathrm{MLBPr}_{7}$ increased in reducing sugars observed from (4.12 to 5.10). $\operatorname{MLBPr}_{1}(33.87 \%)$ got maximum percent increase in total soluble solids of the blended pulp and followed by $\operatorname{MLBPr}_{5}(31.67 \%)$, while $\operatorname{MLBPr}_{7}(19.22 \%)$ got minimum percent increase in blended pulp samples and followed by $\mathrm{MLBPr}_{2}$ (23.61\%). All the data were significantly different for reducing sugars of mango and loquat blended pulp at $(\mathrm{p}<0.05)$. Similar outcomes were observed by Desai et al. (2012), who found increment in reducing sugars of mango pulp during storage study. Besides, Suman et al. (2017) observed an increase in total sugar study. The main reason for the increment of reducing sugars might be the conversion of complex carbohydrates into monosaccharide's.

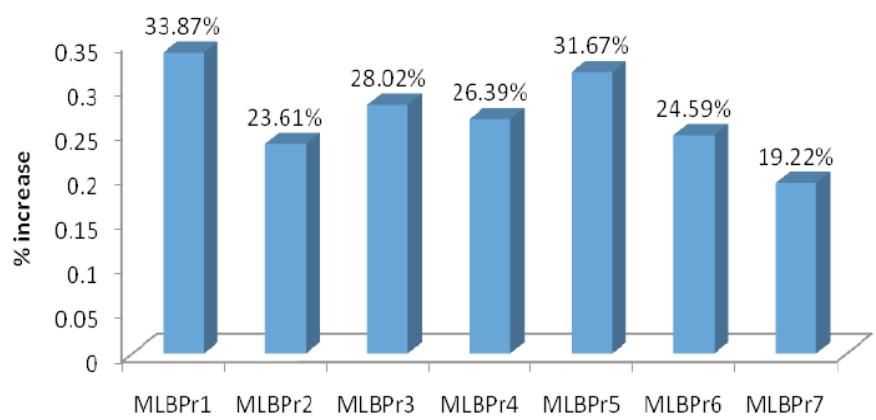

Figure 4: Influence of different food chemical preservatives on the reducing sugars of mango and loquat blended pulp at ambient temperature $\left(25 \pm 2^{\circ} \mathrm{C}\right)$. MLBP: Mango Loquat Blended Pulp.

The mango and loquat blended pulp samples data obtained for non-reducing sugars showed decrease during storage conditions at ambient condition. During storage, the mean values for non-reducing sugars decreased from 5.84 to 4.17. The data for non reducing sugars decreased (Figure 5) were $\mathrm{MLBPr}_{0}$ from (5.85 to 3.02), $\mathrm{MLBPr}_{1}$ from (5.84 to 4.32), $\operatorname{MLBPr}_{2}$ (5.86 to 4.62), for $\mathrm{MLBPr}_{3}$ from (5.84 to 3.40) during six months storage studies. Similarly, non reducing sugars values were recorded for $\mathrm{MLBPr}_{4}$ (5.85 to 4.50), $\mathrm{MLBPr}_{5}$ from (5.85 to 3.91), $\mathrm{MLBPr}_{6}$ from (5.84 to 4.71), and for $\mathrm{MLBPr}_{7}$ non reducing sugars decrease was recorded (5.86 to 4.92). The highest percent decrease was recorded for non reducing sugars in the blended fruit pulp treatments in $\operatorname{MLBPr}_{0}(48.38 \%)$ and followed by $\operatorname{MLBPr}_{3}$ (41.78\%) while the lowest percent decrease in blended fruit pulp treatments was noted in $\mathrm{MLBPr}_{7}$ (16.04\%) and followed by $\operatorname{MLBPr}_{6}$ (19.35\%). All the data were significantly different for non reducing sugars of mango and loquat blended fruit pulp at $(\mathrm{p}<$ 
0.05). Ayub et al. (2010), observed the same results i.e. rise in reducing sugars and a decline in non-reducing sugars in the strawberry fruit juice during storage. This increase might be due to the breakdown of disaccharides into monosaccharides during prolong storage and reactions between acids and fluctuation in temperature (Saleem et al., 2008).

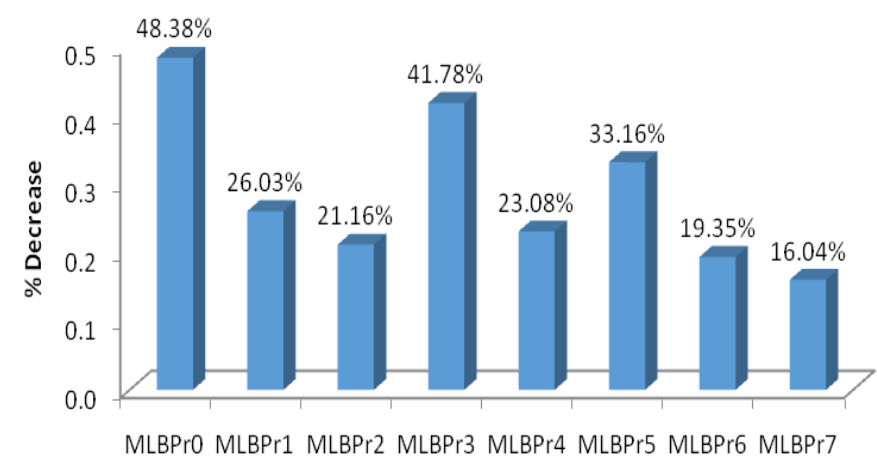

Figure 5: Influence of different food chemical preservatives on the non reducing sugars of mango and loquat blended pulp at ambient temperature $\left(25 \pm 2^{\circ} \mathrm{C}\right)$. MLBP: Mango Loquat Blended Pulp.

\section{Ascorbic acid $(m g / 100 g)$}

The vital element present in every fruit is Ascorbic Acid (Vitamin C). Ascorbic Acid showed decrease during storage conditions at ambient condition. During 180 days of storage, the mean values for ascorbic acid decreased from 43.62 to 13.50 (mg/100g). The data for ascorbic acid decrease (Figure 6) were as $\mathrm{MLBPr}_{0}$ from 43.80 to $0.20, \mathrm{MLBPr}_{1}$ from (43.15 to 13.25), $\mathrm{MLBPr}_{2}$ it was (43.70 to 16.40 ), for $\mathrm{MLBPr}_{3}$ from (42.35 to 10.10 ) during six months storage studies. Similarly, ascorbic acid values were recorded for $\operatorname{MLBPr}_{4}$ (44.60 to 15.00), $\operatorname{MLBPr}_{5}$ from (42.95 to 12.85 ), $\mathrm{MLBPr}_{6}$ from (43.55 to 18.95 ), and for $\mathrm{MLBPr}_{7}$ ascorbic acid decrease was recorded (44.90 to 21.25). The highest percent decrease was recorded for ascorbic acid in the blended fruit pulp treatments in $\operatorname{MLBPr}_{0}(99.54 \%)$ and followed by $\operatorname{MLBPr}_{3}(76.15 \%)$ while the lowest percent decrease in blended fruit pulp treatments was noted in $\operatorname{MLBPr}_{7}$ (52.67\%) followed by $\operatorname{MLBPr}_{6}(56.49 \%)$. All the data were significantly different for ascorbic acid of mango and loquat blended fruit pulp at $(\mathrm{p}<0.05)$. Kumhar et al. (2014) results are in line with studied custard apple pulp and found a decline in ascorbic acid content during a storage period of four months at room temperature. In light of the reports, the decrease in vitamin $\mathrm{C}$ content is mainly owing to oxidative reactions of vitamin $\mathrm{C}$ ascorbic acid to dehydro-ascorbic acid and their further conversion to diketo-gluconic acid due to their enzymatic reactions. Similarly, results were obtained by Ayub et al. (2010) who found a decrease in vitamin $\mathrm{C}$ content of juice treated with different food preservatives at refrigerated temperature during 90 days of storage period.

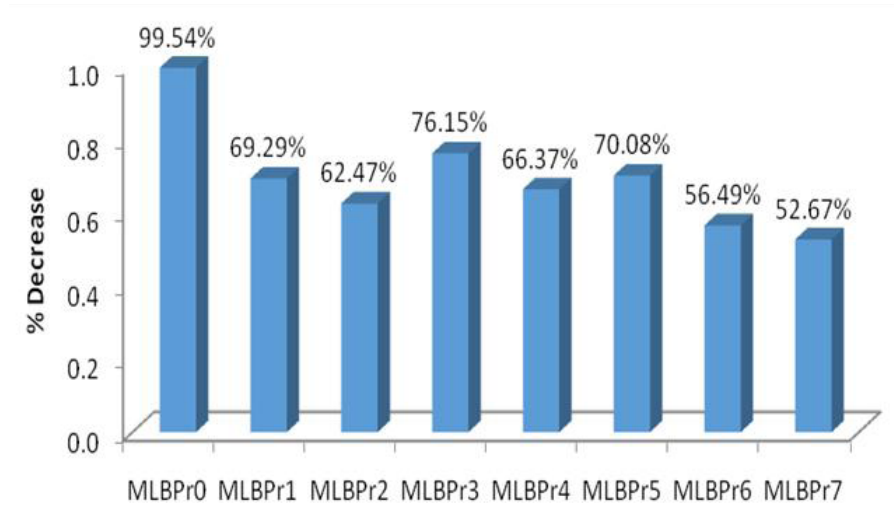

Figure 6: Influence of different food chemical preservatives on the ascorbic acid $(\mathrm{mg} / 100 \mathrm{~g})$ of mango and loquat blended pulp at ambient condition $\left(25 \pm 2^{\circ} \mathrm{C}\right)$. MLBP: Mango Loquat Blended Pulp.

Total phenolic compounds ( $m g$ gallic acid equivalents/100g)

In every fruit product phenolic compounds, contribute a major role owing to their nutritional value. During 180 days of storage, the mean values for total phenolic compounds decreased from 28.43 to 8.96 . The data for total phenolic compounds decrease (Figure 7) were as $\mathrm{MLBPr}_{0}$ from (28.50 to 4.20), $\mathrm{MLBPr}_{1}$ from (28.00 to 8.00), $\mathrm{MLBPr}_{2}$ it was (28.15 to 11.45 ), for $\mathrm{MLBPr}_{3}$ from (28.99 to 8.15) during six months storage studies. Likewise, total phenolic compound values were recorded for $\mathrm{MLBPr}_{4}$ (28.55 to 9.45), $\mathrm{MLBPr}_{5}$ from (28.38 to 6.45), $\mathrm{MLBPr}_{6}$ from (28.10 to 10.10), and for $\mathrm{MLBPr}_{7}$ total phenolic compounds decrease was recorded (28.80 to 13.90). The highest percent decrease was recorded for total phenolic compounds in the blended fruit pulp treatments in $\operatorname{MLBPr}_{0}(85.56 \%)$ and followed by $\operatorname{MLBPr}_{5}(77.27 \%)$ while the lowest percent decrease in blended fruit pulp treatments was noted in $\operatorname{MLBPr}_{7}(51.74 \%)$ and followed by $\operatorname{MLBPr}_{2}$ (59.33\%). All the data were significantly different for total phenolic compounds of mango and loquat blended fruit pulp at $(\mathrm{p}<0.05)$. The outcomes of this research study are in line with the outcomes of Saci et al. (2015) who investigated the influence of storage stability along-with temperature on total phenolic compounds of fruit pulp juices and observed a decreasing trend in total phenolic content of beverages during the entire storage study. The results are similar to the study of Walkowiak-Tomczak (2007) who found a decrease of phenolic contents in fruit pulp juices with six months of storage. $\mathrm{He}$ 
discussed in his report that a decline in total phenolic content might be due to an increment in temperature and oxygen during the storage period of six months.

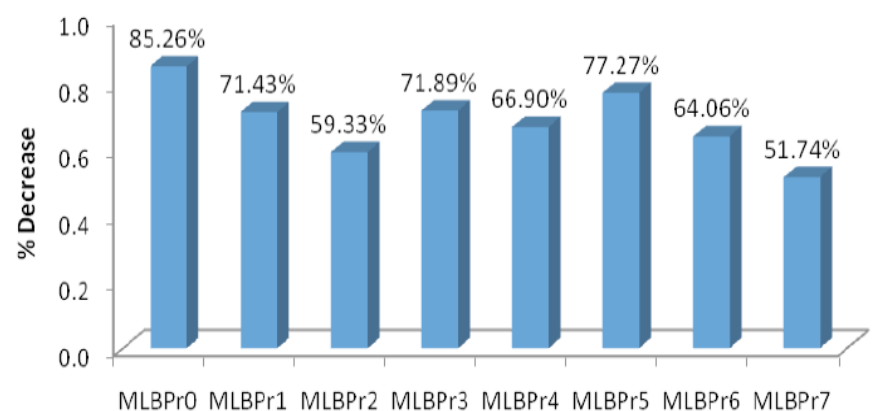

Figure 7: Influence of different food chemical preservatives on phenolic compounds mango and loquat blended pulp at ambient temperature $\left(25 \pm 2^{\circ} \mathrm{C}\right)$. MLBP: Mango Loquat Blended Pulp.

\section{Antioxidant capacity}

In any food, product antioxidants have a vital role due to their health defending feature. During 180 days of storage, the mean values for antioxidant activity decreased from 84.09 to 30.90 . The data for antioxidant activity decrease (Figure 8) were as $\mathrm{MLBPr}_{0}$ from (84.10 to 2.80), MLBPr $\mathrm{r}_{1}$ from (84.19 to 33.23), $\mathrm{MLBPr}_{2}$ it was (84.99 to 36.00), for $\mathrm{MLBPr}_{3}$ from (84.12 to 29.30) during six months storage studies. Similarly, antioxidant activity values were recorded for $\mathrm{MLBPr}_{4}$ (83.17 to 34.12), $\mathrm{MLBPr}_{5}$ from (84.10 to 32.00), $\mathrm{MLBPr}_{6}$ from (83.95 to 38.77), and for $\mathrm{MLBPr}_{7}$ antioxidant activity decrease was recorded (84.12 to 40.99). The highest percent decrease was recorded for antioxidant activity in the blended fruit pulp treatments in $\operatorname{MLBPr}_{0}(96.67 \%)$ and followed by $\operatorname{MLBPr}_{3}(65.17 \%)$ while the lowest percent decrease in blended fruit pulp treatments was noted in $\mathrm{MLBPr}_{7}(51.27 \%)$ and followed by $\mathrm{MLBPr}_{6}$ $(53.82 \%)$. All the data were significantly different for the antioxidant activity of mango and loquat blended fruit pulp at $(\mathrm{p}<0.05)$. The outcomes of this research study are in line with the outcomes of Prabal et al. (2018) who observed a decline in antioxidant activity of fruit pulp during three months of the storage period. Our findings are also in agreement with Hoffmann et al. (2017) who find out the maximum decline in antioxidant activity of blended fruit pulp and nectar during the storage period.

\section{Sensory evaluation}

Color: Sensory evaluation of mango and loquat blended pulp was carried out by a panel of trained judges with nine points hedonic scale during 180 days of storage period. The mango and loquat blended pulp samples data obtained for color score showed decrease during storage. During 180 days of storage, the mean score for color decreased from 9.00 to 6.05 . The data for color score decrease (Figure 9) were as $\mathrm{MLBPr}_{0}$ from (9.00 to 1.00), $\mathrm{MLBPr}_{1}$ from (9.00 to 6.50), $\mathrm{MLBPr}_{2}$ it was (9.00 to 7.50), for $\mathrm{MLBPr}_{3}$ from (9.00 to 4.50) during six months storage studies. Similarly, color score recorded for $\mathrm{MLBPr}_{4}$ (9.00 to 7.45), $\mathrm{MLBPr}_{5}$ from (9.00 to 6.00), $\mathrm{MLBPr}_{6}$ from (9.00 to 7.65), and for $\mathrm{MLBPr}_{7}$ color score decrease was recorded (9.00 to 7.85). The highest percent decline was recorded for the color score in the blended fruit pulp treatments in $\operatorname{MLBPr}_{0}(88.89 \%)$ and followed by $\operatorname{MLBPr}_{3}(50.00 \%)$ while the lowest percent decrease in blended fruit pulp treatments was noted in $\mathrm{MLBPr}_{7}$ (12.78\%) and followed by $\operatorname{MLBPr}_{6}(15.00 \%)$. All the data were significantly different for the color score of mango and loquat blended fruit pulp at $(\mathrm{p}<0.05)$. Our results are in agreement with Durrani et al. (2011) who studied mango pulp preserved with potassium metabisulphite and enhances the shelf life of mango pulp during storage. The color change might be due to the chemical reactions and interaction of chemical preservatives with carotenoids. These results were also supported by Kumari (2016), who observed a decrease in color.

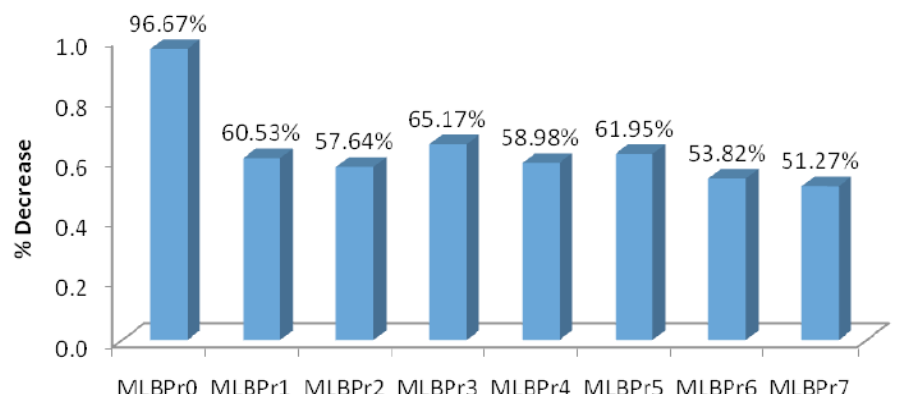

Figure 8: Influence of different food chemical preservatives on the antioxidant activity of mango and loquat blended pulp at ambient temperature $\left(25 \pm 2^{\circ} C\right)$. MLBP: Mango Loquat Blended Pulp.

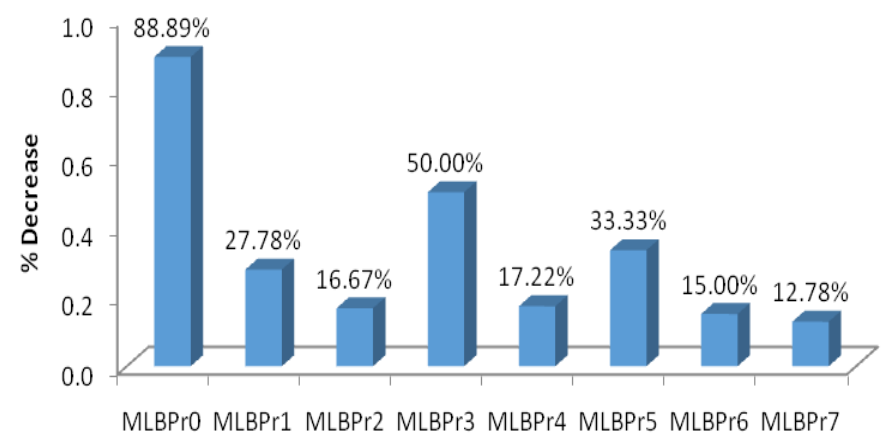

Figure 9: Influence of different food chemical preservatives on the color score of mango and loquat blended pulp at ambient temperature $\left(25 \pm 2^{\circ} \mathrm{C}\right)$. MLBP: Mango Loquat Blended Pulp. 
Taste: The mango and loquat blended pulp samples data obtained for taste score showed decrease during storage conditions at ambient temperature. During 180 days of storage, the mean score for taste decreased from 8.81 to 5.42 . The data for taste score decrease (Figure 10) was as $\mathrm{MLBPr}_{0}$ from (8.85 to 1.00 ), $\mathrm{MLBPr}_{1}$ from (8.70 to 5.85), $\mathrm{MLBPr}_{2}$ it was (8.80 to 6.70), for $\mathrm{MLBPr}_{3}$ from (8.80 to 3.90) during six months storage studies. Similarly, taste score was recorded for $\mathrm{MLBPr}_{4}$ (8.85 to 6.45), $\mathrm{MLBPr}_{5}$ from (8.80 to 5.50), $\mathrm{MLBPr}_{6}$ from (8.85 to 6.90 ), and for $\mathrm{MLBPr}_{7}$ taste score decrease was recorded (8.85 to 7.10). The highest percent decrease was recorded for taste score in the blended fruit pulp treatments in $\operatorname{MLBPr}_{0}(88.70 \%)$ and followed by $\operatorname{MLBPr}_{3}(55.68 \%)$ while the lowest percent decrease in blended fruit pulp treatments was noted in $\operatorname{MLBPr}_{7}(19.77 \%)$ and followed by $\operatorname{MLBPr}_{6}(22.03 \%)$. All the data were significantly different for the taste score of mango and loquat blended fruit pulp at $(\mathrm{p}<0.05)$. Our results are in agreement with Durrani et al. (2011) who studied mango pulp preserved with potassium metabisulphite and enhance the shelf life of mango pulp during storage. The color change might be due to the chemical reactions and interaction of chemical preservatives with carotenoids. The results of Raje et al. (1997) and Hayat et al. (2005) are in line with our results who reported that the taste and flavor of mangoes and apple pulp consecutively decreasing with temperature and humidity at $25-32^{\circ} \mathrm{C}$ and $70-$ $75 \%$. The results of this research study are also in agreement with Mehmood et al. (2008) who find out a decline in the taste score during sensory evaluation for fruit pulp stored at room condition.

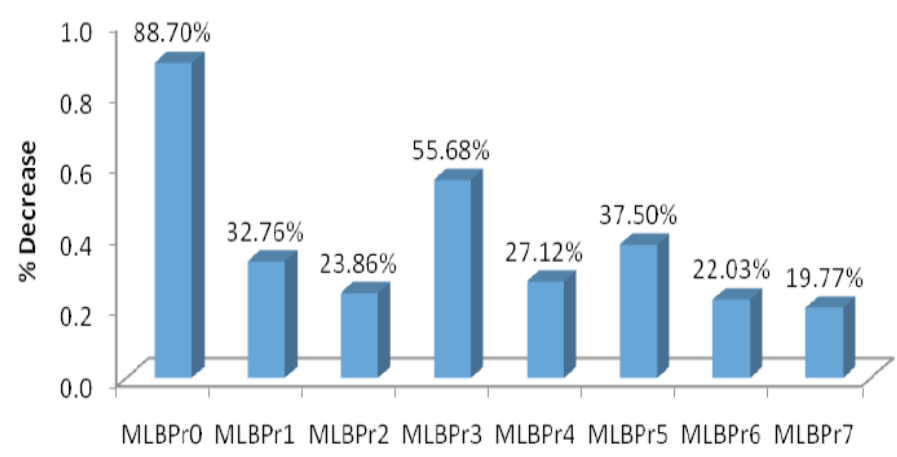

Figure 10: Influence of different food chemical preservatives on the taste score of mango and loquat blended pulp at ambient temperature $\left(25 \pm 2^{\circ} C\right)$. MLBP: Mango Loquat Blended Pulp.

\section{Overall acceptability}

Overall acceptability has the main importance in any food product development. During 180 days of storage, the mean score for overall acceptability decreased from 8.88 to 5.32. The data for overall acceptability score decrease (Figure 11) were as $\mathrm{MLBPr}_{0}$ from (8.90 to 1.00$), \mathrm{MLBPr}_{1}$ from (8.85 to 5.70$), \mathrm{MLBPr}_{2}$ it was (8.85 to 6.70), for $\mathrm{MLBPr}_{3}$ from (8.90 to 3.65) during six months storage studies. Similarly, overall acceptability score was recorded for $\mathrm{MLBPr}_{4}$ (8.90 to 6.00), $\mathrm{MLBPr}_{5}$ from (8.85 to 5.35), $\mathrm{MLBPr}_{6}$ from (8.90 to 7.00), and for $\mathrm{MLBPr}_{7}$ overall acceptability score decrease was recorded (8.90 to 7.20). The highest percent decrease was recorded for the overall acceptability score in the blended fruit pulp treatments in $\operatorname{MLBPr}_{0}(88.76 \%)$ and followed by $\operatorname{MLBPr}_{3}$ (58.99\%) while the lowest percent decrease in blended fruit pulp treatments was noted in $\mathrm{MLBPr}_{7}$ (19.10\%) and followed by $\operatorname{MLBPr}_{6}(21.35 \%)$. All the data were significantly different for the overall acceptability score of mango and loquat blended fruit pulp at $(\mathrm{p}<0.05)$. Our research work results are in conformity with Shahnawaz et al. (2012) who find out decrease in overall acceptability of mango sea buckthorn blended pulp during storage study. Similar results were obtained Saeed et al., (2010). Also, the results of Khurshid and Zeb (2008) are same with our results who stated decline in the score of overall acceptability of low caloric apple drink at refrigeration condition.

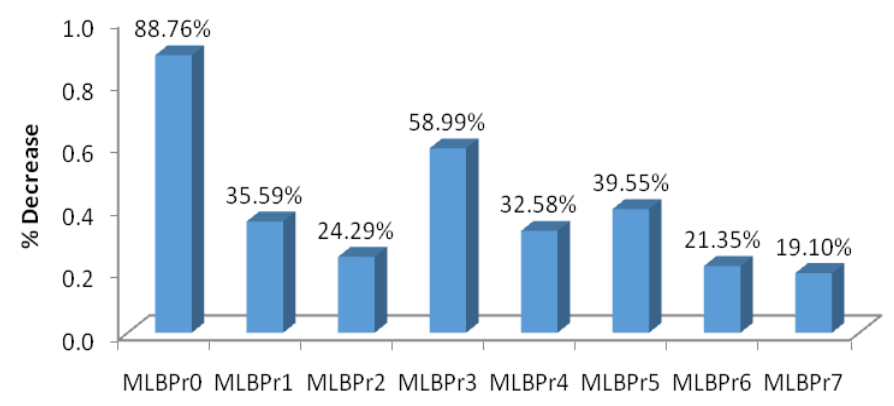

Figure 11: Influence of different food chemical preservatives on the overall acceptability of mango and loquat blended pulp at ambient condition $\left(25 \pm 2^{\circ} C\right)$. MLBP: Mango Loquat Blended Pulp.

\section{Conclusions and Recommendations}

In this research study it was concluded that Mango and Loquat blended pulp in mixing proportion of 60:40 comparatively secured high overall acceptability and shown increase in the nutritional profile of blended pulp. The combined effect of chemical preservatives on shelf life of mango and loquat blended pulp was more successful as compared to alone and also compared to control. The effect of collective dosage of chemical food preservatives i.e. $0.033 \% \mathrm{PS}, 0.033 \% \mathrm{SB}$ and $0.01 \%$ $\mathrm{KMS}$ on treatment $\mathrm{MLBP}_{\mathrm{r} 7}$ and $\mathrm{MLBP}_{\mathrm{r} 6}$ of mango 
loquat blended pulp samples were more effectual for enhancing the overall quality of mango and loquat blended pulp and showed maximum stability in physiochemical study and over-all acceptability as compared to other treatments during six months storage period. It is recommended that other food preservation methods should be adopted where the use of chemical preservatives reduced for extending the shelf life of mango and loquat blended pulp and their products. It is also recommended that controlled temperature should be used for preservation of fruit pulp.

\section{Novelty Statement}

Novelty of this research is to find out the value addition of loquat pulp with mango pulp to overcome the postharvest losses of fruits. Novelty of this research shall provide an opportunity to food industry as loquat fruit has no commercial utilization.

\section{Author's Contribution}

Rukhsar Ali is a principal author and $\mathrm{PhD}$ scholar, who did research, analysis, experiments and wrote the manuscript. Ali Muhammad is major supervisor, who supervised the study.

\section{Conflict of interest}

The authors have declared no conflict of interest.

\section{References}

Akhtar, S., S. Mahmood, S. Naz, M. Nasir and M.T. Sultan. 2009. Sensory evaluation of mangoes (Magnifera Indica L.) grown in different regions of Pakistan. Pak. J. Bot., 41(6): 2821-2829

AOAC, 2012. Official methods of analysis of the association of official analytical chemists, 2012; $19^{\text {th }}$ ed., 1058-1059.

Ayub, M., J. Ullah, M. Ali and A. Zeb. 2010. Evaluation of strawberry juice preserved with chemical preservatives at refrigeration temperature. Int. J. Nut. Metabolism., 2(2): 2732.

Cai, C., K. Chen, W. Xu, W. Zhang, X. Li and $\mathrm{X}$. Ferguson. 2006. Effect of $1-\mathrm{MCP}$ on post harvest quality of loquat fruit. Posthar. Biol. Tech., 40(2): 155-162. https://doi. org/10.1016/j.postharvbio.2005.12.014

Desai, C.S., A.K. Naik and J.M. Patil. 2012. Study on physiochemical properties of some early mango (Mangiferaindica $\mathrm{L}$ ) varieties for pulp processing. Beverages Food World, 39(2): 5557.

Durrani, Y., A. Zeb, M. Ayub, W. Ullah and A. Muhammad.2011. Sensory evaluation of mango (chaunsa) pulp preserved with addition of selected chemical preservatives and antioxidant during storage. Sarhad J. Agric., 27(3): 471-475.

Federico, F., G. Danidela, V. Patricia, G. Rui, P. Rafael, A.C. Edvan, M.S. Rosa and B.A. Paula. 2009. Improved loquat (Eriobotrya japonica Lind1.) cultivars: Variation of phenolics and antioxidative potential. Food Chem., 114: 1019-1027. https://doi.org/10.1016/j. foodchem.2008.10.065

FAOSTAT, 2020. Food and Agriculture Organization of the United Nations, FAO Statistics, Rome, Itlay.

Gerbaud, P., 2008. Close- Up. Mango. Fruitrop. 153: 10-35.

Goupy, P., M. Hgues, P. Bovin and M.J. Amiot. 1999. Antioxidant composition and activity of barley (Hordeumvugare) and malt extracts of isolated phenolic compounds. J. Sci. Food Agric., 79:1625-1634. https://doi.org/10.1002/ (SICI)1097-0010(199909)79:12<1625::AIDJSFA411>3.0.CO;2-8

Hasegawa, P.N., A.F. Faria, A.Z. Mercadante, E.A. Chagas, R. Pio, F.M. Lajolo, B.R. Cordenunsi and E. Purgatto. 2010. Chemical composition of five loquat cultivars planted in Brazil. Ciência e Tecnologia de Alimentos, 30(2): 252-559. https://doi.org/10.1590/S010120612010000200040

Hayat, I., T. Masud and H.A. Rathore. 2005. Effect of coating and wrapping materials on the shelf life of apple (Malus domestica cv. Borkh). Int.J. Food Saf., 5: 24-34.

Hussain, I., A. Zeb, I. Shakir and A.S. Shah. 2008. Combined effect of potassium sorbate and sodium benzoate on individual and blended juices of apricot and apple fruits grown in Azad Jammu and Kashmir. Pak. J. Nutr., 7(1): 181185. https://doi.org/10.3923/pjn.2008.181.185

Hoffmann J.F., G.P. Zandona, P.S.D. Santos, C.M. Dallmann, F.B. Madruga, C.V. Rombaldi and F.C. Chaves. 2017. Stability of bioactive compounds in Butia( ButiaOdorata) fruit pulp and nectar. Food Chem., 237: 638-644. https:// doi.org/10.1016/j.foodchem.2017.05.154 
Jonathan, H.C. and C. Liliam. 2009. Loquat growing in the Florida home landscape, UF University of Florida IFAS Extension.

Jain, P.K. and P.K. Nema. 2007. Processing of pulp of various cultivars of guava (Psidiumguajava L.) for leather production. Agric. Eng. Int. Council Large Elect. Syst., 9: 1-9.

Khurshid, A. and A. Zeb. 2008. Preparation and quality analysis of low caloric apple drink. Thesis. Dept. Food Sci. Tech. Univ. Agric. Peshawar.

Kumhar, D.S., S. Pareek and K.D. Ameta. 2014. Effect of antioxidants and storage temperatures on browning and quality of custard apple (Annona suqamosa L.) pulp. J. Sci. Ind. Res., 73: 622-626.

Kumar,M., R.K. Godara,D. Singh,D.V.Pathak and S. Singh. 2015. Effect of different preservatives on the storage of ber pulp. Int.J. Farm Sci., 5(4): 222- 228.

Kumari, Y., 2016. Studies on effect of blending impact of guava (Psidiumguajava L.) and papaya (carica papaya 1.) pulp on recipe standardization of blended nectar and RTS (ready to serve) beverages. M. Sc. (Hort) thesis. Dept. Fruit Sci. Indira Gandhi Krishi Vishwavidyalaya Raipur.

Larmond, E., 1997. Laboratory method of sensory evaluation of food. Publication 1977, Can. Dept. Agric. Ottawa. No.95/2/EC on food additives other than colours and sweeteners. Eur. Parliament and Council Directive.

Mehmood, Z., A. Zeb, M. Ayub, N. Bibi, A. Badshah and Ihsanullah. 2008. Effect of Pasteurization and Chemical preservatives on the quality and shelf stability of Apple Juice. Am. J. Food Tech., 3(2): 147-153. https://doi. org/10.3923/ajft.2008.147.153

Mir, K.B., A. Riaz, I. Ullah, S. Hussain and N. Ullah. 2019. Effect of preservatives and storage temperatures on the quality of mango slices dipped in sugar solution. J. Food Process Tech., 10: 784.

Patricia, N.H., F.d.F. Adelia, Z.M. Adriana, A.C. Edvan, P. Rafael, M.L. Franco, R.C. Beatriz and P. Eduardo. 2010. Chemical composition of live loquat cultivars planted in Brazil. Cienc. Technol. Aliment., Compians, 30(2): 552-559. https://doi.org/10.1590/S010120612010000200040

Prabal, P.S., A.D. Tripathi, D.C. Rai, N. Kumar and U.P. Singh. 2018. To study the shelf life of
Aloe vera fortified mango RTS with different time and temperature combinations on its organoleptic and functional properties. Pharm. Innov. J., 7(3): 91-97.

Parveen, S., I. Bushra, K. Humaira, S. Shazia and M.A. Azhar. 2014. Value addition: A tool to minimize the post-harvest losses in horticultural crops.Green J.Agric. Sci.,4(5):195-198.https:// doi.org/10.15580/GJAS.2014.5.042914208

Raje, L., S. Sherlekar, K. Ramakrishnan, V.C. Malshe and G. Subbulakshmi. 1997. Post harvest preservation of mangoes by controlled chemical release agents and adsorbent. Acta Hort., 455: 622- 628.https://doi.org/10.17660/ ActaHortic. 1997.455.80

Saleem, B.A., A.U. Malik, M. Maqbool, I.U. Din, M. Farooq and I.A. Rajwana. 2008. Early winter spray of low biuret urea improves marketable yield and fruit quality of sweet oranges. Pak. J. Bot., 40: 1455-1465.

Saeed, A., M. Riaz, A. Ahmad and A. Nisar. 2010. Physico-chemical, microbiological and sensory stability of chemically preserved mango pulp. Pak. J. Bot., 42(2): 853-862.

Sadasivam, S. and A. Manickam. 2008. Biochemical methods, $3^{\text {rd }}$ Edn, New Age International (P) Limited Publishers, pp. 203-206.

Saci, F., L. Meziant and H. Louaileche. 2015. Effect of storage time and temperature on the healthpromoting substances and antioxidant activity of two commercial fruit based-beverages. Int. J. Bioinf. Biomed. Eng., 1(2): 118-122.

Shahnawaz, M., A. Wali, Y. Durrani, M. Ayub, A. Muhammad, M.R. Khan and H. Khan. 2012. Refrigerated storage studies of mango seabucthorn blended pulp with selective chemical preservatives and ginger extract. Int. J. Food Nut. Sci., 1(1): 1-7.

Steel, R.G.D. and J.H. Torrie. 1997. Principles and procedures of statistics. McGraw Hill Book Co. NewYork.Stat.Proc.Agric.Res. $\left(2^{\text {nd }} E d\right) \cdot p p .8-22$.

Suman, K.Y., D.K. Sarolia, S. Pilania, H.R. Meena and L.N. Mahawer. 2017. Studies on keeping quality of preserved guava pulp during storage. 2017. Int. J. Curr. Microbiol. App. Sci., 6(3): 1235-1242. https://doi.org/10.20546/ ijcmas.2017.603.142

Walkowiak-Tomczak, D., 2007. Changes in antioxidant activity of black chokeberry juice concentrate solutions during storage. Acta Sci. Pol. Technol. Aliment., 6: 49-55. 